This paper is the accepted, pre-publication version that is due to appear in a Special Edition of Social Theory and Health entitled, 'Engaging Experience: Mobilising Personal Encounters with Mental Ill-Health in Knowledge Production', due to be published early 2019. 
Tactical Authenticity in the Production of Autoethnographic Mad Narratives

\section{Simon P. Clarke ${ }^{1}$ and Colin Wright ${ }^{2}$}

${ }^{1}$ School of Education, University of Nottingham, Jubilee Campus, Wollaton Road, Nottingham NG8 1BB, UK. Email: simon.clarke@nottingham.ac.uk

${ }^{2}$ Associate Professor of Critical Theory, Department of Culture, Film \& Media, University of Nottingham B41a, Trent Building, University Park, Nottingham, NG7 2RD, UK. Email: colin.wright@nottingham.ac.uk

Correspondence to:

Dr Simon Clarke, Department of Psychology, Chaucer 4019, Nottingham Trent University, 50 Shakespeare Street, Nottingham NG1 4FQ, UK; Tel: +44 (0)115 848 4547; Fax: +44 (0)115 848 2390; Email: simon.clarke@nottingham.ac.uk 


\title{
Tactical Authenticity in the Production of Autoethnographic Mad Narratives
}

\begin{abstract}
First-person accounts of madness and of encountering psychiatric services provide important sociocultural and psychological knowledge about the subjectivity of distress. The importance of such accounts is often based upon a claim of the authenticity of personal experience. However, authenticity is a highly heterogeneous concept: a popular current manifestation of the discourse of authenticity is in positive psychology, where it is often underpinned by humanist assumptions such as the rational autonomous self. The post-structuralist critique of humanism challenged such essentialist notions some time ago and has been adopted explicitly by research methodologies such as autoethnography. The purpose of this article is to argue that this tension - between the value of methods such as autoethnography that offer a legitimate source of knowledge regarding the subjective experience of madness on the one hand, and the problems with an essentialist conception of the 'authentic' self on the other can be addressed by the deployment of a reconceptualised form of authenticity based on Gayatri Spivak's (1988) notion of 'strategic essentialism', especially when modified by Michel De Certeau's (1984) distinction between 'tactics' and 'strategies'. The implications of this distinction in terms of developing autoethnographies of distress is then discussed.
\end{abstract}

Key words: authenticity; madness; autoethnography; narratives; positive psychology; mental health. 


\section{Introduction}

R. D. Laing wrote in the preface to The Divided Self that he wanted to "make madness, and the process of going mad, comprehensible" (Laing, 1960, p. 9). The problem, Laing argued, was that the categories used by biological psychiatry often bear little relationship to the actual experience of patients. Thus, by presenting madness in purely reductionist biological language, our understanding of what it is like to go mad becomes entirely mystified. Although Laing did not have direct experience of madness himself when he wrote The Divided Self, the purpose of making madness comprehensible to those without first-person experience has arguably been a key driver behind the growth in psychiatric 'illness memoirs', 'autopathographies' and 'patient narratives' of psychiatric experiences. Such accounts provide an important source of knowledge about the experiences of madness from the 'inside' (Woods, 2012). There are several well-known narratives that have influenced the development of clinical theory and practice (Schreber, 1903; Greenberg, 1964; Saks, 2007), along with a plethora of lesser known works used in medical training programmes (see Hornstein, 2008). Such accounts "have a vital role to play in our comprehending, mapping, and negotiating of madness" (Baker et al, 2010, p. 2).

More recently, the emancipatory potential of first-person accounts of madness has been recognised in terms of offering "new ways of understanding mental distress and of working with people to identify new ways of living with or overcoming distress and providing services” (Faulkner, 2017, p 509). This ‘experiential knowledge', Faulkner (2017) argues, "has a significant contribution to make where some of the basic premises of professional knowledge are strongly contested" (p. 509).

First-person accounts thus afford something important and unique that performs two distinct, but at times related, functions: to provide information and insight into an often 
ineffable and mysterious experience; and to challenge the very paradigm of bio-medical psychiatry itself from the perspectives of those who use, or have used, services. More recently, the methodology of autoethnography has emerged that often blends these two aims together in mental health research. We would argue, and this article will try to show, that such attempts are often predicated on an argument of authenticity.

Yet authenticity, precisely as a term with extensive cultural capital, is hardly neutral or homogenous, relating as it does to a whole range of practices, values and concepts in public life (Vannini and Williams, 2009). It is also a term that is laden with considerable conceptual baggage (Ferrara, 2009), to the point that some writers have dispensed with it completely, whilst also trying to establish the value of first-person accounts on an entirely separate basis (e.g., Grant et al, 2013). In our opinion, these latter attempts have not been very successful, as we will argue more fully below.

In what follows therefore, we wish to outline a theory of authenticity that we believe may support the valorisation of first-person accounts of knowledge in mental health autoethnographies without falling into several persistent traps. In doing so, we will be making the following claims:

1. Authenticity is a heterogeneous concept, but one which encompasses a series of values and practices that do cohere;

2. Homogenising the concept of authenticity, conversely, opens the door to methodological difficulties and dubious practices and affiliations;

3. Attempts to support first-person knowledge claims inevitably centre on some implicit variation of what we will call 'the argument from authenticity', even when they explicitly deny it; 
4. A modified concept of authenticity can be a viable basis to support first-person knowledge claims in a non-essentialist way - we will call this approach 'tactical authenticity'.

We will begin by locating the concept of authenticity in terms of its linguistic, historical and conceptual background. To indicate some of the traps associated with it, we will then show how the recent positive psychology movement has re-appropriated the concept of authenticity in service of a neo-positivist and neo-liberal agenda. We will then explore how the poststructuralist critique of humanism has already complicated the idea of authenticity. In the final section, we develop from these debates the notion of a tactical concept of authenticity which, we argue, may be politically useful in both asserting, and deploying in transformational ways, the value of autoethnographic accounts of madness.

Before proceeding however, we would like to clarify our chosen terminology. We have deliberately opted to use the term 'madness' for the specific purposes of this article. Although controversial, this term is preferable, in this context, to the narrow medical symptomology represented by other clinical definitions such as 'mental illness' or 'psychiatric disorders' (Baker et al, 2010). 'Madness' encompasses the broader social, psychological and cultural dimensions which are often the ones that matter most to the subjects experiencing mental distress (Burstow, 2015). With the emergence of sub-disciplines such as 'Mad Studies' and political movements focussed on the emancipation of service-users from stultifying institutional discourses (Starkman, 2015), the choice of 'madness' already reflects the strategic approach to discourse we will be arguing for.

We also recognise that various terms have been used to describe the recipients of mental health service treatment, including 'patient', 'service-user', 'consumer', 'client' and 'survivor' (Beresford, 2007). In recognition of this, we have therefore decided to use both 
'service user' and 'survivor' interchangeably here to refer to people experiencing or who have experienced madness or distress within a mental health institutional context.

\section{Authenticity: Linguistic and Cultural Roots}

Unsurprisingly, the origins of the word 'authenticity' are complex and diverse. It first appeared in English from the mid- $14^{\text {th }}$ Century onwards when it had the sense of 'authorised', 'authenticated' or 'recognised by legitimate authorities' (for example, the acceptance of new doctrine by the Church authorities). It was borrowed from the Old French word autentique, which had the related meaning of 'canonical', as in, entitled to be included in the cannon of sacred knowledge. The French autentique derived in turn from the Medieval Latin term authenticus, which itself was directly derived from the Greek term authentikos, meaning 'original, genuine, principal'. The root of authentikos is authentes, which combines autos ('self') and hentes ('doer, being') to mean - in contrast to its later relation to external authorities such as the church - 'acting on one's own authority'. This Greek word, hentes, comes in turn from the Proto-Indo-European word sene, meaning to 'accomplish' or 'achieve', implying an action that produces recognition. Indeed, some interpreters also cite the Greek word authenteo which means to have 'full power over' to the extent of 'usurping another' or even 'committing a murder' (Trilling, 1972).

Therefore, there is a tension at the heart of our conception of authenticity: between authenticity defined as 'accurate representation of a reality' and authenticity defined as 'recognition or authority'. Arguably, our own era privileges the former definition; for example, the Oxford English Dictionary currently defines authenticity as being "in accordance with fact, as being true in substance". Given these diverse etymological roots, it is no surprise that modern usage beyond the dictionary definition is equally diverse. 'Authentic' 
can mean 'real' in the sense of not a copy (e.g., an 'authentic' or verified Van Gogh painting, with a corresponding market value); or it can denote the subjective fidelity of an artistic representation (e.g., Wilfred Owen's poetry presents 'authentic' depictions of the experiences of war); or it can be used to describe the integrity of a person or behaviour (e.g., Donald Trump is an 'authentic politician' in that he 'tells it like it is' etc.). In terms of personality descriptors, we generally describe someone as authentic in terms of their genuineness, forthrightness, honesty and congruence. One could still understand authenticity through the ancient Greek rhetorical theory of ethos: it is what gives truth-value to someone's speech or discourse because of the integrity and relevant experience of the speaker. It is not just that the content of the speech is factually true, but that the one who speaks is especially - perhaps even uniquely - entitled to speak on this topic by dint of their personal experience.

\section{Authenticity and Existentialism}

Whilst the term and the meanings it conveys have undeniable social currency, authenticity is more than just a cultural value or useful social heuristic: it has also enjoyed status as a recurring concept in philosophical discourse. As a fully formulated intellectual understanding of the world, modern academic concepts of authenticity derived largely from the work of continental philosophy in the 1930s through to the 1950s, particularly Martin Heidegger and Jean Paul Sartre (Kaufmann, 1975). Both explicitly used the term 'authenticity' in their work and were influenced by the works of Søren Kierkegaard and Friedrich Nietzsche, who also foregrounded issues of individual subjectivity and personal agency (Medlock, 2012).

Early Heidegger formulated his version of authenticity, in the second section of Division Two of Being and Time (1998), according to the neologism eigentlichkeit, which names the attitude in which one engages in projects as one's own (eigen). Heidegger was 
playing on the ordinary German term 'eigentlich', meaning 'truly', which has the root 'eigen' meaning 'own' or 'proper to'. Adding 'keit' to eigentlich turns it into a transitive project, an unfolding which also implies a process of 'owning' or 'propering'. Therefore, for Heidegger, authenticity involves taking ownership of one's unfolding life in terms of one's relation to a trans-individual Being. This would be in contrast to the majority of people who are content with a form of inauthentic 'thrownness' into the everydayness of 'the-they' which alienates them from Being.

For Sartre (1948), relatedly, authenticity consists in avoiding the 'bad faith' that comes from denying the inescapable tensions between choice and circumstance. The authentic person here is the one who makes genuine existential choices but also takes responsibility for their consequences, despite the horror or disgust they may feel towards the ultimate meaninglessness of the universe (Kaufmann, 1975). Where Heidegger tends to think of authenticity as an alignment with Being such that the Cartesian cogito is left behind, Sartre's existentialist humanism grounds authenticity in a cogito that knows it is "condemned to be free": after the death of God, the only authentic position is to refuse to let oneself off the hook with merely inherited worldly moralities, and instead confront the ethical stakes in every one of our choices and actions. If Heidegger's authenticity implies a participation in the epochal Being of a world, Sartre's authenticity invokes an isolated individual defying worldly conventions - so much so that in his Being and Nothingness the prisoner is presented as a paragon of authentic freedom.

Heidegger and Sartre's work was subjected to sustained criticism on both ethical and philosophical grounds. Adorno (2003), in particular, developed a Marxist critique that characterised Heidegger's 'jargon of authenticity' as an ahistorical form of obscurantism that promises the 'unconcealment of Being' but in fact "gives itself over either to the market, to balderdash, or the prevailing vulgarity" (2003, pg. xix): in other words, Heidegger's notion of 
authenticity served ideological purposes, obscuring real historical contradictions. According to Adorno then, the jargon of authenticity could ultimately be used to legitimise both the bureaucratic tyranny of Nazism and the exploitative language of advertising in late Capitalism. If Adorno has a contrasting notion of 'authenticity', it is a negative authenticity that confronts the non-identity at work in identity (1973). Regarding Sartre, Jacques Derrida (1972) pointed out that he never quite dispensed with the notion of a Cartesian self that makes choices, and analyses those choices, somehow outside of the constraints of societal context or language. For Derrida, Sartre's project of an existential humanism for the era following the death of God was thus "nothing other than the metaphysical unity of man and God, the relation of man to God, the project of becoming God as the project of constituting humanreality", so much so that "Atheism changes nothing in this fundamental structure" (Derrida, 1972, p. 116). Sartrean existentialist authenticity for Derrida would smack of onto-theology and metaphysics.

As these philosophical debates illustrate, the tensions within authenticity between the representation of an essential reality on the one hand, and questions of authority and ownership on the other, are played out in relation to fundamental philosophical questions such as the very nature of thought. They also show how the notion of authenticity is tied up with concepts of individual subjectivity and (non)identity. As the next section will show, these tensions become even more marked in humanist and positive psychology.

\section{Authenticity and Positive Psychology}

Although existentialism was beginning to decline in influence in Europe around the 1960s, several of its main theoretical tenets were to be revived, albeit in a culturally idiosyncratic way, in American humanist psychology. Carl Roger's articulation of the 'actualising 
principle' at the centre of human striving owed much to Kierkegaard, whilst Abraham Maslow's famous 'hierarchy of needs' and 'peak experiences' similarly borrowed from Nietzsche (Medlock, 2012). Of course, the profoundly disturbing, even deconstructive, nature of Kierkegaard and Nietzsche's thought is noticeably absent from Rogers and Maslow; there, the individual is conceived of in terms of 'positive striving' and the drive to 'congruence' rather than in terms of their relation to sin (Kierkegaard) or power (Nietzsche).

If American humanism seemed to borrow from an existentialist language shorn of its more pessimistic and challenging elements, then this probably represented something of the culture of both the United States and the growing discipline of psychology. The spectre of the essentialist Cartesian self, indirectly present in Sartre's thought, is very much in the foreground in empirical psychology (Parker, 2007). It is little surprise then that the concept of authenticity would experience something of a revival through a marriage between American humanism and empirical psychology in the new sub-discipline of positive psychology.

According to its proponents, positive psychology is "the scientific and applied approach to uncovering people's strengths and promoting their positive functioning" (Snyder and Lopez, 2006, p. 3). Distancing themselves from what they perceived to be mainstream psychology's preoccupation with the 'negative' aspects of human pathology, positive psychology instead focusses upon the 'positive' aspects of human nature, conceived by Seligman and Csikszentmihalyi (2000) as positive subjective experiences, positive individual traits, and civic virtues. These 'civic virtues' are tied to Classical character traits such as wisdom, courage, humanity, justice, temperance and transcendence, all formulated according to the basic assumptions of positive psychology: that there is a human "nature"; that action proceeds from character; and that character comes in two forms, both equally fundamental bad character and good virtuous character (Seligman, 2002a, p. 125). Seligman (2002b) summarises the positive psychology perspective on human functioning thus: "When well- 
being comes from engaging our strengths and virtues, our lives are imbued with authenticity" (p. 14).

If the assumptions underlying positive psychology seem somewhat simplistic, this is probably due in part to a tendency in psychology to formulate concepts that can be easily subjected to quantitative evaluation (Parker, 2007). A more recent trend in the growing conceptual amalgamation between humanist and positive psychology is the rise of empirical measurement of key humanist concepts (Joseph, 2015). On this basis, the concept of authenticity has been developed from Rogers' (1961) notion of congruence and investigated as an 'individual difference variable' leading to formulations of the 'authentic personality' (Wood et al, 2008). In this 'new' approach to authenticity, authentic living can be understood as "being true to oneself in most situations and living in accordance with one's values and beliefs" (Wood et al, 2008, p. 386), with psychopathology becoming the degree to which "the person experiences self-alienation between conscious awareness and actual experience (the true self)" (p. 386). Finally, "the extent to which one accepts the influence of other people" along with "the belief that one has to conform to the expectations of others" (p. 382) marks the degree to which one is able to 'resist external authority' - the third component in Wood et al's (2008) tripartite conception of authenticity. This 'authentic personality' has then been measured in a number of ways familiar to empirical psychology: questionnaires, laboratory experiments and mood reporting via digital technology (Lenton, Bruder et al, 2013; Lenton, Slabu et al, 2013; Davis et al, 2015).

Empirical psychology literature has tended to look at associations between authenticity and popular positive psychology concepts such as 'wellness', 'flourishing' or 'flow' and this probably reflects the tacit assumption that authenticity can be used as a benchmark for other positive psychology concepts such as 'wellbeing' and 'self-actualisation' (Joseph, 2015). This approach has some rather obvious limitations. It is entirely possible that 
white supremacists in the United States, for example, could experience 'congruence' between their actual experience of hating black people and their values of ethnic purity, whilst also resisting the external authority of Liberal political consensus through hate rallies and armed militias, but we have yet to come across a positive psychology study that has looked at authenticity and flourishing amongst the alt-right. This example may be extreme perhaps, but it does illustrate the tendency amongst some psychologists to assume their concepts are 'objective' and thus apolitical (Parker, 2007), whilst simultaneously employing standards of measurement and theoretical constructs that are tied very closely to political practices that are far from neutral or benign (e.g., Wright, 2013; Wright, 2014; Davies, 2016; Cederström and Spicer, 2009).

There are further theoretical and methodological shortcomings in authenticity research within the narrow disciplinary confines of psychology. For instance, people who are 'inauthentic' are, by definition, highly unlikely to be aware of their supposed inauthenticity and hence highly unlikely to reflect this quality in the type of measurements used by psychologists. The difficulty appears to reside in how the complexity of identity, and the varied manifestations of selfhood in everyday life, may alter considerably according to different contexts and the different roles people occupy in these contexts (Ferrara, 2009). This leads however to the paradox of an inauthentic study of authenticity, one which ultimately relies on a binary notion of self that is built upon a true/false dichotomy often taken for granted by authenticity researchers. Psychologists have reprised the essentialist nature and meaning of a 'core self' (Parker, 2007), but this is especially true of a core self that is tied to the much narrower idea of living according to a pre-set criterion of 'strengths' and 'virtues'.

\section{Autoethnography and Authenticity}


These complexities have led some psychological authenticity researchers to conclude that the best way of studying authenticity may be across a whole lifespan using autobiographical lifestory narratives (Harter, 2005). Here, at least some form of developmental continuity in behaviour can be established beyond the immediate context of the psychological survey or experiment. As Harter (2005) elaborates:

[N]arrative construction is a continuous process as we not only craft but also revise the story of our lives, creating blueprints that facilitate architectural development of the self. In so doing, one's life story can also emerge as a true story (p. 391).

In other words, the complexity of narrative construction and reconstruction, along with its relationship with the ongoing process of revision, mean that the 'truth' of the story (i.e., its 'authenticity') can emerge in the process of telling. Is the future for the study of authenticity therefore to be found in narrative approaches, and not in empirical psychology?

In many ways, the place at which Harter arrives above probably represents more continuity with the concept's phenomenological and existential origins - i.e., narrative as selfmaking or autopoiesis as opposed, ultimately, to market research methods - which is probably why much of the research from the humanist stable tends to be qualitative (Joseph, 2015). Yet, narrative research has its own narrative of authenticity concerning its legitimacy and this is particularly the case with narrative research that comes under the general heading of 'autoethnography'. It is to these approaches that we will turn now.

Frustrated by research that failed to recognise the invisible and unacknowledged, yet very real, presence of the researcher (Ellis and Bochner, 2000), alongside disillusionment with what was perceived to be the increasingly sequestered and elitist position of academic discourse, autoethnography sought to recapture something of the vitality of 'lived experience' 
in the research enterprise, with the researcher's own experience becoming the primary 'data' (Bochner, 2001). "I become a detached spectator" write Ellis and Bochner (2006) about traditional methods, "I become only a head, cut off from my body and emotions. There's no personal story to engage me" (p. 481).

In contrast, autoethnography focussed on lived experienced which prioritised both the stories of the researcher and researched, but also the first-person perspective as an important way of writing academic research (Ellis, 2004). This move was predicated on what Grant et al. (2013) depicted as "a shift from a single, monolithic conception of what should constitute scholarly work in favour of a developing pluralism” (p. 3). As Art Bochner (2001), a prominent autoethnographic researcher, argues, narratives "have a major role to play in the ill person's quest for authenticity, a journey he or she may never reach but cannot resist." (p. 147).

In these terms, and at first glance, narrative approaches would seem to provide an ideal basis for an empirical study of human life and subjectivity, both in terms of developing knowledge but also in terms of an ethical imperative to honour the experience of those being researched. The argument deployed here, against the perceived hegemony of academia and for the restoration of the first-person perspective, was one of authenticity. However, such 'arguments from authenticity' are not without issues, as we will show in the next section.

\section{Issues with Autoethnography}

Unfortunately, many autoethnographic approaches fall prey to a set of problems that also underlie the empirical positive psychology approaches - namely, the assumptions surrounding the self, particularly the true/false binary, or even the notion that there is such thing as a 'true' self to begin with, outside of the way in which the 'self' is performed in a particular social 
context. Paul Atkinson (2009) developed a scathing critique of narrative research which contends that "narratives are treated as proxies for the direct apprehension of subjective, personal experience" (S1.3) and are thus "treated as sources of authenticity, grounded in the biographical particularities of speaking subjects" (2.11). One of the issues Atkinson highlights is the notion of supposed narrative exemplarity, which ultimately results in a reductionism that leads to "the equation of the social with the personal" (2.14) whereby personal expression, via the first-person perspective only, takes the place of systematic and rigorous social analysis. Atkinson (2012) refers to such approaches as 'sentimental realism' whereby "the narrating speaker is celebrated as an atomised subject" (2.14) with an emotional truth to convey.

Given these problems, it is no surprise that some autoethnographers dispense with the concept of authenticity entirely. For example, Grant et al. (2013) call for "the poststructural narrating voice of the emergent "I"' over the "narrative voice of the predetermined I" (p. 8) in order to "show how subjectivity is produced rather than to display a privileged and secure, transcendent narrative identity position" (ibid p.8). They also favour privileging of the distinctive voice, including the use of irony, humour, mockery, silence and textual disruption of the singular voice.

However, such an enterprise still leads Grant et al. (2013) to try to establish validity for narrative research against the criticisms of positivism. There is an important dilemma here: how can narrative research be legitimised when the main argument for its validity has resided in an argument for authenticity? It appears to be something of a contradiction when Grant et al. (2013) repudiate the role of authenticity so fully in their chapter because of its humanist assumptions of presence, and then assert that: 
Arguably, academic-, discipline- and profession-based practice based on personal knowledge and experience is more credible, ethical, imbued with integrity, empathic and potentially effective. This marks the difference between implicational and propositional knowledge: between knowing, feeling, connecting and doing, from the heart, based on personal experience, rather than solely on the basis of rationally acquired information. (p. 11).

Although Grant et al. (2013) have succinctly summarised why autoethnography is such an important methodology, theirs is still an 'argument from authenticity' that surreptitiously employs the same categories used by earlier, humanist researchers. Of course, it is possible that Grant et al's (2013) arguments are based on an overly-simplistic reading of Derrida (1976), maintaining, as they do, some of the binaries of presence (e.g., feeling/intellect, implicational/propositional etc.) that Derrida was at pains to deconstruct in his work, but the question remains: if we attempt to abandon notions of authenticity on the basis that they re-inscribe humanist notions of presence, on what basis can we still emphasise the strategic importance of autoethnography?

\section{Tactical Authenticity and Autoethnographic Mad Narratives}

The psychiatric survivor and mental health researcher who wants to employ autoethnographic methods when voicing their experience could well be caught in a peculiar double-bind. On the one hand, the values of such approaches may lie in challenging stigma whilst also providing the opportunity to educate professionals, lay people and students as to the actual conditions and experiences of people who use services (Russo, 2016). On the other hand, there is a risk 
of falling into unhelpful binary oppositions when invoking concepts such as 'voice' or 'lived experience' (Voronka, 2016) that risk creating a different set of problems.

The postcolonial theorist, Gayatri Spivak (1990), recognised a similar dilemma in the position she often found herself occupying as a 'spokesperson' for 'subaltern' Indian women in the United States, but it was a dilemma she attempted to turn to advantage:

But it is not possible, within discourse, to escape essentializing somewhere. The moment of essentialism or essentialization is irreducible. In deconstructive critical practice, you have to be aware that you are going to essentialize anyway. So then strategically, you can look at essentialisms, not as descriptions of the way things are, but as something that one must adopt to produce a critique of anything. (p. 51)

In other words, the essentialist categories of 'Indian' and 'woman' may indeed be problematic, but they do provide the ('Indian', 'woman') speaker with a certain degree of legitimisation in the mainstream discourse, a place from which to speak and from which some form of resistance and challenge can be mobilised. As Spivak (1988) elaborates, "it is within the framework of a strategic interest in the self-alienating displacing move of and by a consciousness of collectivity, then, that self-determination and an unalienated selfconsciousness can be broached" (p. 14). Could the same approach work for autoethnographic mad narratives, that is, legitimisation of the survivor's 'voice' based upon this 'strategic' version of authenticity?

Whilst this approach may be superficially attractive, there are at least three problems when applied to madness narratives. Firstly, madness is an inherently deconstructive experience; when speaking or writing about such experiences there can be "a disjunction 
between the content to be narrated and the possibilities inhering in conventional narrative forms" (Stone, 2004, p. 18). Secondly, madness is not a homogenous experience; some experiences may be constructed differently in different contexts (e.g., religious voice hearers in church and voice-hearing psychiatric patients in hospital) and so-called 'mad identity' incorporates a vast range of conditions, experiences and treatments (Miller, 2017). It is thus difficult to essentialise an experience as heterogeneous as extreme psychological distress, when the conditions for some experiences (e.g., eating disorders) are bound to differ significantly from others (e.g., psychosis). As Miller (2017) observes, "the experience of psychiatric oppression in its various forms is presumably an important commonality, but there seems no reason to presume any further unanimity" (p. 17).

Thirdly, and perhaps most importantly, it is questionable whether intervening through essentialising experiential or identity categories actually works. Sometimes, the place you are given to speak from is simultaneously a major constraint on what you can say, or be heard as saying. Indeed, Spivak eventually rejected the concept of strategic essentialism herself precisely because "my notion just simply became the union ticket for essentialism" (Danius et al, 1993, p. 35): in other words, it led to the very essentialist tendencies she was seeking to avoid in the first place. In the field of mental health, where differences between experiences are even less likely to be anchored to singular identity categories due to the heterogeneous nature of 'distress', "using experience and identity as a commodity to gain entry into systems of power", as Voronka (2016) observed when laying claim to authenticity in experience, can result in "entrenching and naturalizing difference" (p. 199).

When discussing her eventual rejection of the concept of strategic essentialism, Spivak added a further important qualifying observation: "As to what is meant by strategy, no one wondered about that" (Danius et al, 1993, p. 35). This raises an important question regarding the limitations of 'strategy' itself that may provide a clue as to why her project was 
unsuccessful. A possible solution, we would argue, might be found in the work of Michel De Certeau, specifically in his distinction between 'strategies' and 'tactics'. De Certeau (1984) calls 'strategy' "the calculation (or manipulation) of power relationships that becomes possible as soon as a subject with will and power (a business, an army, a city, a scientific institution) can be isolated" (p. 35-6). Strategy is thus an essentially military term, having to do with territories and the top-down imposition of forms of rationality and practice that exert an ongoing control. By contrast, De Certeau defines 'tactics' as “a calculated action determined by the absence of a proper locus" (p. 37), that is, without a territory of its own, which also occurs in a different temporality, one that seizes the opportune moment (what the ancient Greeks called Kairos) that appears within the metronymic regularity of rationalised time (Chronos). If strategy is determined by those with power, tactics are the operations used by those with little power who nevertheless find ways to subvert and adapt strategies to suit their own ends.

Tactics are thus adaptations to environments or territories that are shaped by strategy but move in opposition to it, against its grain. For example, town planners might determine the streets of a city with expectations of how people will use them, but those who know the environment, the 'users', will spontaneously adapt the routes they take to suit their experience (e.g., taxi drivers using shortcuts, or so-called 'desire lines' that traverse planned pathways). In this way, "strategy is transformed into tactics" (p. 37) within its very terrain. De Certeau's work thus identifies, within institutionalised forms of power, an immanent possibility of subversion which is not reducible to the forms of representation through which such power works, and yet necessarily accompanies them.

One could also define the relationship between psychiatry and the serviceuser/survivor movement in a similar way: although psychiatry as a discipline maintains a presence through its strategies of place (hospitals and university faculties), observation 
(measurement technologies) and bodies of knowledge (classification systems), service-user movements have nevertheless been able to gain a foothold within these institutions and move, precisely, across them somewhat obliquely. An example of this tactical appropriation of strategy can be seen in neo-liberal policies of patient engagement, which do give patients an institutional space in which to speak, at least in the UK where service-user representation in the National Health Service has in fact become mandatory (Rose, 2015), and thus to speak 'against the grain'. Illustrating this, Rose et al (2003) have shown that when participants were interviewed about their experience of electroconvulsive therapy (ECT) by service-user researchers rather than by professional researchers or clinicians, 'satisfaction' turned out to be significantly lower than had been found previously, thereby challenging the asserted legitimacy of ECT (Rose, 2008). In this instance, the tactics based upon contextualised, experiential knowledge which were then employed using the language of strategy (i.e., 'evidence-based practice' and ultimately 'customer feedback'), were able to subvert the knowledge claims of the dominant strategic form of power, resulting in concrete changes to policy in terms of how ECT was administered. As Rose (2008) later elaborated, "We intervene on the terrain drawn by psychiatry and try to re-shape its priorities in a user-focused direction" (p. 642). This example shows that tactical interventions can occupy the same terrain as the strategies that make up these fields, but precisely by displacing the identitycategories that we believe are part of the problem.

Autoethnographic mad narratives may offer a similar tactic in terms of intervening into the discourses of psychiatry via the discourse of authenticity. As Charles Taylor (1991) recognised, "the moral force of the ideal of authenticity" (p. 17) is still "one of the constitutive ideals of modern culture" (p. 18). Similarly, the liberal representational stance of Western culture (i.e., 'I respect your experience and I'm listening to what you have to say about it') provides opportunities for autoethnographic mad narratives to occupy a space 
within psychiatric research and practice, but in order to tactically disrupt it, rather as occupations are an important tactic among activists.

Such approaches might therefore lay claim (or, indeed, re-claim) the original meaning of the term 'authenticity' which emphasises the importance of gaining recognition, and establishing authority for one's experience, precisely there where the 'owness' of experience is put into radical question. In autoethnographic madness narratives, such tactics might take the form of using the 'official' discourse of psychiatry (e.g., clinical notes) presented alongside thick descriptions of the experiences of survivors and carers (e.g., Clarke, 2018) in order to show how the everyday experience of a psychiatric patient is transformed into a discourse that serves strategic power. Another approach might juxtapose fragmented personal accounts with theoretical analysis and reflections on method in a 'layered account' of psychological distress (Rambo, 2013) without imposing the 'panoptical' view of any particular 'voice'. Finally, another approach might present multiple viewpoints in order to force discussion on the very controversial issue of suicide (Webb, 2010). Taken together, these works point the way forward to possibilities of employing personal experience in a tactical way whilst taking into account Spivak's point, a propos of Derrida, that the metaphor of 'voice' itself carries the danger of essentialising 'representationalism' (Landry and Maclean, 1992). As opposed to its strategic counterpart, tactical authenticity, we would argue, makes it possible to give voice to the radical heterogeneity and singularity of the experience of madness.

\section{Conclusion}

This article explored the concept of authenticity related to mad narratives in the research method of autoethnography. Despite varied etymological and cultural roots, authenticity has 
been used to mean primarily 'real' as in 'not a copy' or, less commonly, to mean pertaining to 'authorship' or 'authority'. These tensions have been reflected in philosophical debates concerning identity and subjectivity and have found expression more problematically in recent empirical positive psychology research. Some researchers have attempted to reclaim the notion of authenticity, principally through the methodology of autoethnography, but these attempts often result in a deployment of the same categories (often surreptitiously) that affect positive psychology. Although these issues are confronted through Gayatri Spivak's notion of 'strategic essentialism', a possible solution was proposed in Michel De Certeau's distinction between 'strategies' and 'tactics'. The article concluded by providing potential examples of tactical authenticity in autoethnographic mad narratives. 


\section{References}

Adorno, T.W. (2003) The Jargon of Authenticity. Evanston: Northwestern University Press.

Adorno, T.W. (1973) Negative Dialectics, trans. E.B. Ashton. London: Routledge.

Atkinson, P.A. (2009) Illness narratives revisited: the failure of narrative reductionism. Sociological Research Online, 14(5)16, published online 30 November 2009, doi: http://www.socresonline.org.uk/14/5/16.html

Atkinson, P.A. (2013) Ethnographic writing, the avant-garde and a failure of nerve. International Review of Qualitative Research 6(1): 19-35.

Baker C., Crawford P., Brown, B. J., Lipsedge, M. and Carter R. (2010) Madness in Post1945 British and American Fiction. London: Palgrave.

Beresford, P. (2007) The role of service user research in generating knowledge-based health and social care: From conflict to contribution. Evidence \& Policy 3(3): 329 - 341.

Bochner, A. (2001) Narrative's virtues. Qualitative Inquiry 7(2): 131-157.

Burstowe, B. (2015) A rose by any other name. In: B.A. LeFrançois, R. Menzies and G Reaume (eds.) Mad Matters. Toronto: Canadian Scholars’ Press, pp. 79-90.

Cederström, C. and Spicer, A. (2009) The Wellness Syndrome. London: Polity.

Clarke, S.P. (2018) Madhouse and the whole thing there. Qualitative Research in Psychology, advance online publication 16 February 2018, doi: 10.1080/14780887.2018.1429989

Danius, S. Jonsson, S. and Spivak, G.C. (1993) 'An Interview with Gayatri Chakravorty Spivak'. Boundary 2, 20(2): pp. 24-50.

Davies, W. (2016) The Happiness Industry: How the Government and Big Business Sold Us Well-Being. London: Verso. 
Davis, W.E., Hicks, J.A., Schlegel, R.J., Smith, C.M., and Vess, M. (2015) Authenticity and self-esteem across temporal horizons. The Journal of Positive Psychology 10(2): 116126.

De Certeau, M. (1984) The Practice of Everyday Life, trans. Steven Rendall. Los Angeles: University of California Press.

Derrida, J. (1972) The Ends of Man, Margins of Philosophy, trans. A. Bass. Chicago: University of Chicago Press, 1982.

Derrida, J. (1976) Of Grammatology, trans. G.C. Spivak. Baltimore, MD: Johns Hopkins University Press.

Ellis, C. (2004) The Ethnographic I: A Methodological Novel about Autoethnography. Walnut Creek, CA: AltaMira Press.

Ellis, C. and Bochner, A.P. (2006) Analyzing analytic autoethnography: An autopsy. Journal of Contemporary Ethnography 35(4): 429-449.

Faulkner, A. (2017) Survivor research and Mad Studies: the role and value of experiential knowledge in mental health research. Disability \& Society 32(4): 500-520

Ferrara, A. (2009) Authenticity without a true self. In: P. Vannini and J. P. Williams (eds.) Authenticity in Culture, Self, and Society. Farnham, UK: Ashgate, pp. 21-36

Frank, A. (2005) What is dialogical research, and why should we do it? Qualitative Health Research 15(7): 964-974.

Grant, A., Biley F. and Walker, H. (eds.) (2011) Our Encounters with Madness. Ross-onWye: PCCS Books.

Grant, A., Short, N. P. and Turner, L. (2013) Introduction: Storying Life and Lives. In: N.P. Short, L. Turner and A. Grant (eds.) Contemporary British Autoethnography. Rotterdam, NL: SensePublishers, pp. 1-16. 
Greenberg, J. (1964) I Never Promised You a Rose Garden. New York: Holt.

Harter, S. (2005) Authenticity. In: C.R. Snyder (ed.) Handbook of Positive Psychology. Cary, NC: Oxford University Press, pp. 382-394.

Heidegger, M. (1998) Being and Time, trans. J. Macquarrie and E. Robinson. Oxford: Blackwells.

Hornstein, G.A. (2008) Bibliography of first-person narratives of madness in English http://www.mtholyoke.edu/acad/assets/Academics/Hornstein_Bibliography.pdf Accessed 6 July, 2016.

Joseph, S. (2015) Positive Therapy: Building bridges between positive psychology and person-centred psychotherapy. Hove: Routledge.

Kaufmann, W. (1975) Existentialism from Dostoevsky to Sartre. New York: New American Library

Laing, R.D. (1960) The Divided Self. London: Penguin.

Landry, D. and Maclean, G. (eds.) (1996) The Spivak Reader. London: Routledge.

Lenton, A. P., Bruder, M., Slabu, L., and Sedikides, C. (2013) How Does “Being Real” Feel? The Experience of State Authenticity. Journal of Personality 81(3): 276-289.

Lenton, A. P., Slabu, L., Sedikides, C., and Power, K. (2013) I feel good, therefore I am real: Testing the causal influence of mood on state authenticity. Cognition \& Emotion 27(7): 1202-1224.

Medlock, G. (2012) The evolving ethic of authenticity: from humanistic to positive psychology. The Humanistic Psychologist 40(1): pp. 38-57. 
Miller, G. (2017) Madness decolonized?: madness as transnational identity in Gail Hornstein's 'Agnes's Jacket'. Journal of Medical Humanities, accessed online 20 February 2017, doi: https://doi.org/10.1007/s10912-017-9434-8

Parker, I. (2007) Revolution in Psychology: Alienation to Emancipation. London: Pluto Press. Rambo, C. (2013) Twitch: A performance of chronic liminality. In S.H. Jones, T.E. Adams, and C. Ellis (eds.) Handbook of Autoethnography. Walnut Creek, CA: Left Coast Press Inc., pp. 627-638

Rogers, C.R. (1961) On Becoming a Person: A Therapist's View of Psychotherapy. New York: Houghton Mifflin.

Rose, D., Wykes, T., Leese, M., Bindman, J. and Fleischmann, P. (2003) Patients' perspectives on electroconvulsive therapy: systematic review. British Medical Journal 326(7403): 1363-1368.

Rose, D. (2008) Madness Strikes Back. Journal of Community \& Applied Social Psychology 18(6): $638-644$.

Rose, D. (2015) The contemporary state of service-user-led research. The Lancet Psychiatry 2(11): 959-60.

Russo, J. (2016) In dialogue with conventional narrative research in psychiatry and mental health. Philosophy, Psychiatry, \& Psychology 23(3): 215-228.

Saks, E. (2007) The Center Cannot Hold: My Journey through Madness. London: Virago.

Sartre, J-P. (1948) Existentialism and Humanism, trans. P. Mairet. London: Methuen.

Sartre, J-P. (2003) Being and Nothingness: An Essay on Philosophical Ontology, London: Routledge. 
Schreber, D.P. (1903) Memoirs of my Nervous Illness. New York: New York Review of Books, 2000

Seligman, M.E.P. (2002a) Positive psychology, positive prevention, and positive therapy. In: C.R. Snyder and S.J. Lopez (eds.) Handbook of Positive Psychology New York, NY: Oxford University Press, pp. 3-9.

Seligman, M.E.P. (2002b) Authentic Happiness. New York, NY: The Free Press.

Seligman, M.E.P. and Csikszentmihalyi, M. (2000) Positive Psychology. American Psychologist 55(1): 5-14.

Snyder, C.R. and Lopez, S. J. (2006) Positive Psychology: A Scientific and Practical Exploration of Human Strengths. Los Angeles, CA: Sage.

Spivak, G. C. (1988) Subaltern Studies. In R. Guha and G.C. Spivak (eds.) Selected Subaltern Studies. Oxford: Oxford University Press, pp. 3-32.

Spivak, G.C. (1990) The Post-Colonial Critic: Interviews, Strategies, Dialogue. S. Harasym (ed.). New York: Routledge.

Starkman, M. (2015) The movement. In: B.A. LeFrançois, R. Menzies and G Reaume (eds.) Mad Matters. Toronto: Canadian Scholars’ Press, pp. 27-37

Stone, B. (2004) Towards a writing without power: notes on the narration of madness. Auto/Biography 12(1): 16-33.

Taylor, C. (1991) The Ethics of Authenticity. Cambridge, MA: Harvard University Press.

Trilling, L. (1972) Sincerity and Authenticity. Oxford: Oxford University Press.

Vannini, P. and Williams, J.P. (2009) Authenticity in culture, self, and society. In: P. Vannini and J.P. Williams (eds.) Authenticity in Culture, Self, and Society. Farnham, UK: Ashgate, pp. 1-20 
Voronka, J. (2016) The politics of 'people with lived experience': Experiential authority and the risks of strategic essentialism. Philosophy, Psychiatry, \& Psychology 23(3):189201.

Webb, D. (2010). Thinking About Suicide: Contemplating and Comprehending the Urge to Die. Ross-on-Wye: PCCS Books.

Wood, A.M., Linley, A.P., Maltby, J., Baliousis, M. and Joseph, S. (2008) The authentic personality: A theoretical and empirical conceptualization and the development of the authenticity scale. Journal of Counseling Psychology 55(3): 385-399.

Woods, A. (2012) 'Rethinking "Patient Testimony" in the Medical Humanities: The Case of Schizophrenia Bulletin's First Person Accounts'. Journal of Literature and Science 6(1): $38-54$.

Wright, C. (2002) Centrifugal Logics: Eagleton and Spivak on the Place of 'Place' in Postcolonial Theory'. Culture, Theory and Critique 43(1): 67-82.

Wright, C. (2013) Against flourishing: Wellbeing as biopolitics, and the psychoanalytic alternative. Health, Culture and Society 5(1): 20-35.

Wright, C. (2014) Happiness studies and wellbeing: A Lacanian critique of contemporary conceptualisations of the cure. Culture Unbound 6(4): 791-813.

Word count (excluding title, abstract and key words): 7,000 words

Date: $23 / 05 / 2018$ 